\title{
The Design Application of Physical Outcome's Theory on The HoSPITAL OF MOTHER AND CHILd IN SURAKARTA
}

\author{
Penerapan Physical OUTCOME TheORY \\ Pada Desain Rumah Sakit Ibu dan ANaK di Surakarta
}

\author{
Glabella Ersyara Ramadhani ${ }^{1^{*}}$, Ahmad Farkhan ${ }^{2}$, Leny Pramesti ${ }^{3}$ \\ Program Studi Arsitektur, Fakultas Teknik, Universitas Sebelas Maret ${ }^{1}$ \\ bella.ersya@gmail.com* \\ Program Studi Arsitektur, Fakultas Teknik, Universitas Sebelas Maret $^{2}$ \\ Program Studi Arsitektur, Fakultas Teknik, Universitas Sebelas Maret ${ }^{3}$
}

\begin{abstract}
Women and Children Hospital is an useful healthcare facility to improve the health of Indonesian people especially for women, mothers and children. The lack of adequate health facilities in Indonesia for mothers and children, especially in the city of Solo, makes the number of health cases concerning them are still poorly handled and thorough. Therefore, it needs a special health facility that handles the problem, namely Women and Children Hospital with concept that can solve the problem. The appropriate theory for solving the problem is the Physical Outcome Theory (derived from the concept of Healing Environment).That theory serves to help patients in the hospital, to feel comfortable and safe to be treated in it. The research method used is applied research, through the exploration of initial ideas and data collection which then concluded to be a guide in the design analysis. The results of Physical Outcome Theory implementation in buildings, realized through the processing siteplan design, building facade, interiors, and exteriors.
\end{abstract}

Keywords: hospital, women and children hospital, physical outcome theory, healing environment

\section{PENDAHULUAN}

Rumah Sakit Ibu dan Anak adalah sebuah fasilitas kesehatan khusus yang diperuntukkan untuk para ibu hamil, wanita yang mengalami gangguan kesehatan reproduksi, dan anak-anak di bawah umur 18 tahun. Menurut Departemen Kesehatan Indonesia tahun 2014, Angka kematian Ibu dan Anak di Indonesia tingginya bisa mencapai 400 jiwa per tahun. Hal itu menunjukkan bahwa, fasilitas kesehatan di Indonesia masih tergolong kurang. Ditambah lagi dengan program PONEK (Pelayanan Obstetrik dan Neonatal Emergensi Komprehensif) yang sedang gencar-gencarnya dilakukan oleh pemerintah. Program tersebut guna membantu menangani pasien ibu dan anak yang sifatnya emergency agar dapat lebih tertangani dengan baik dan selamat. Masyarakat di kota Solo pun juga semakin menuntut untuk mendapatkan pelayanan kesehatan yang lebih berkualitas seperti di kotakota lain di Indonesia. Hal-hal tersebut menjadi alasan mendasar mengapa diperlukannya Rumah Sakit Ibu dan Anak di kota Solo ini.

Sedangkan, untuk mengurangi angka kematian dan mempercepat penyembuhan pasien pada saat berada di Rumah Sakit, tentunya dibutuhkan sebuah suasana dan ruang yang mendukung, dan tentunya menggunakan standar desain yang tepat untuk bangunan 
rumah sakit. Berikut adalah standar yang diperlukan untuk memenuhi kriteria Rumah Sakit khusus (Ibu dan Anak) menurut Peraturan Menteri Kesehatan Nomor 56 tahun 2014 :

a. Area pelayanan seharusnya bersifat fungsional satu dengan yang lainnya.

b. Pelayanan darurat letaknya harus menjamin kecepatan dan ketepatan akses dan mempunyai pintu masuk yang terpisah. Area UGD harus terletak pada area depan atau muka dari tapak Rumah Sakit dan mudah terlihat dari luar tapak Rumah Sakit. Untuk tapak Rumah Sakit yang berbentuk memanjang mengikuti panjang jalan raya maka pintu masuk ke dalam area UGD harus terletak pada pintu masuk yang pertama kali ditemui oleh pengguna kendaraan untuk masuk kearea Rumah Sakit. Untuk bangunan Rumah Sakit yang berbentuk bangunan bertingkat banyak yang memiliki ataupun tidak memiliki lantai bawah tanah (Basement) maka perletakan UGD harus berada pada lantai dasar (Ground Floor) atau area yang memiliki akses langsung kepada area parkir.

c. Pelayanan administrasi hendaknya berdekatan dengan pintu utama rumah sakit. Kantor pengelola rumah sakit dapat terletak pada area khusus.

d. Pelayanan operasi hendaknya terletak dan dirancang tidak tergganggu oleh kebisingan dan dapat mencegah aktifitas yang menimbulkan bising.

e. Pelayanan klinik anak diletakkan berdekatan dengan pelayanan kebidanan.

f. Pelayanan persalinan terletak dan dirancang untuk mencegah lalu lintas aktivitas yang tidak berhubungan. Ruang persalinan hendaknya tidak bising dan steril. Ruang perawat sebaiknya terletak pada lokasi yang dapat mengamati pergerakan pasien.Perawat hendaknya terpisah tetapi mempunyai akses yang cepat dari ruang persalinan.

g. Pelayanan perawatan hendaknya terpisah dari zona public. Ruang perawat hendaknya terletak pada lokasi yang dapat mengamati pasien, dengan rasio minimal satu ruang perawat untuk setiap 35 unit tempat tidur. Pada setiap ruang harus tersedia wastafel dengan air mengalir.

h. Jumlah tempat tidur untuk RS khusus minimal $25 \mathrm{TT}$.
Sedangkan, teori yang akan digunakan untuk memecahkan issue-issue tadi adalah Physical Outcome Theory, yang berasal dari turunan konsep Healing Environment, yang memiliki arti sebuah penciptaan suasana ruang yang sedemikian rupa guna untuk mempercepat proses penyembuhan pasien dan untuk membuat pasien merasa lebih nyaman berada di fasilitas tersebut (Djikstra, 2009). Sedangkan dalam Healing Environment itu sendiri terdapat teori Physical Outcome, yaitu teori yang bertujuan untuk menyembuhkan pasien di rumah sakit secara jasmani dan rohaninya juga. Teori ini memiliki beberapa aspek yang dapat membantu mempercepat penyembuhan pasien baik secara jasmani maupun rohani tadi. Aspekaspek tersebut nantinya diterapkan dalam Interior dan Eksterior bangunan rumah sakit. Aspek-aspek yang termasuk dalam Physical Outcome Theory tersebut adalah :

\section{a. Nature}

Nature yang dimaksud adalah alam sekitar atau buatan yang berada di sekitar dan di dalam site. b. Fresh Air

Fresh Air adalah Udara bersih yang berada di sekitar dan di dalam site, baik yang alami maupun buatan seperti dari air conditioner.

c. Noise

Noise ini memiliki artian tingkat kebisingan yang ada di site sebaiknya tingkatannya rendah agar tidak mengganggu kenyamanan pasien.

d. Light

Light yang dimaksud disini adalah cahaya matahari yang masuk ke dalam site dan cahaya buatan yang ada di dalam site.

e. Psycologycal Aspect

Aspek psikologi yang dimaksud adalah aspek yang dapat mempengaruhi pikiran pasien seperti pemilihan warna, pemilihan tekstur, dan peletakan aromatheraphy.

Semua aspek diatas juga memberikan hasil yang sama pada penelitian lain, yakni semua itu memiliki andil yang cukup dalam membantu menyembuhkan pasien baik secara rohani maupun jasmani dengan dibantu aspek lain berupa dukungan keluarga, dan kecakapan staff rumah sakit (Berg, 2005). 


\section{METODE}

Metode penelitian yang digunakan adalah penelitian terapan (applied research) melalui pendekatan deskriptif kualitatif. Pemahaman Physical Outcome Theory diawali dengan mengamati fenomena-fenomena yang ada di sekitar yaitu mengenai penyakit yang dialami ibu hamil dan anak-anak, mengenai psikologi perilaku ibu hamil dan anak-anak pula, dan kemudian dilanjutkan dengan tinjauan data mengenai angka kematian ibu dan anak, data preseden rumah sakit yang sudah ada di Surakarta terutamanya, kemudian teori teori yang berkaitan dengan Healing Environment terutama mengenai Physical Outcome Theory. Sumber data primer pada penelitian ini berupa hasil kajian Physical Outcome Theory yang didapat melalui tinjauan pustaka, jurnal maupun artikel-artikel terkait. Pembahasan pada penelitian terapan lebih terfokus pada penerapan Physical Outcome Theory pada perancangan desain bangunan.

Teori ini didapat melalui kajian konsep bangunan Healing Environment, yaitu tipikal desain bangunan yang bertujuan untuk mempercepat penyembuhan pasien di Rumah Sakit melalui pengaruh lingkungan di sekitarnya. Kemudian, di dalam teori tersebut terdapatlah aspek-aspek yang nantinya akan diterapkan ke aspek desain bangunan seperti siteplan, fasad, interior, secara tepat dan sesuai dengan fungsi bangunan itu sendiri, yaitu sebagai bangunan Rumah Sakit Ibu dan Anak di Surakarta.

\section{HASIL DAN PEMBAHASAN}

Langkah yang dilakukan adalah menerapkan aspek-aspek yang terdapat dalam Physical Outcome Theory pada setiap bagian bangunan Rumah Sakit Ibu dan Anak di Surakarta ini. Berikut adalah bagan yang menunjukkan aspek apa saja yang diterapkan pada bagian-bagian bangunan Rumah Sakit Ibu dan Anak di Surakarta ini:

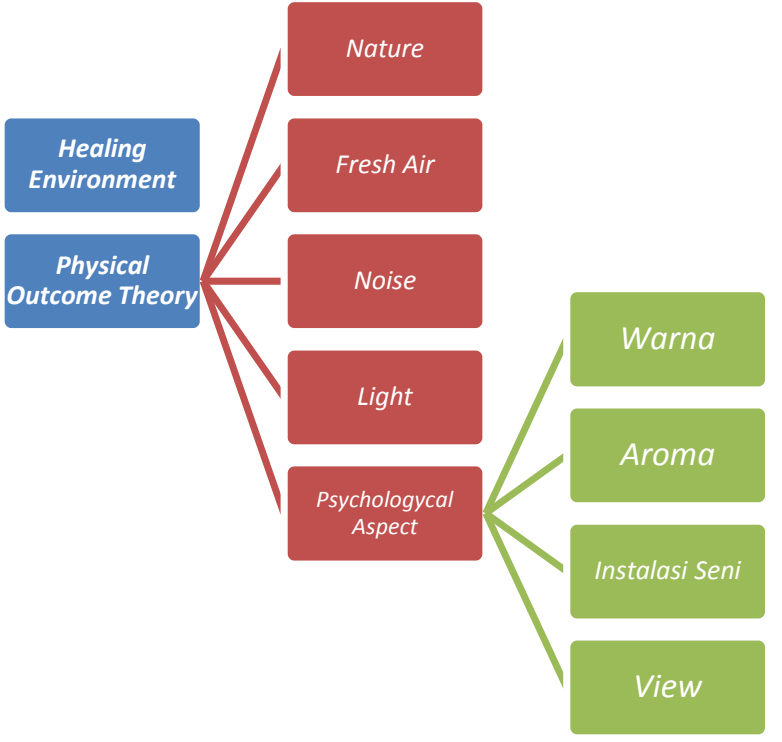

Gambar 1. Bagan yang menunjukkan aspek apa saja yang diterapkan pada ruang-ruang di dalam Rumah Sakit Ibu dan Anak di Surakarta

Di bawah ini adalah tabel yang menunjukkan apa sajakah kelompok ruang yang berada di Rumah Sakit Ibu dan Anak ini beserta luasannya :

\begin{tabular}{|l|l|c|}
\hline No. & \multicolumn{1}{|c|}{ Kelompok Ruang } & Luas \\
\hline 1 & Area Penerimaan & $2.646 \mathrm{~m}^{2}$ \\
\hline 2 & $\begin{array}{l}\text { Ruang Operasi dan } \\
\text { Persalinan (termasuk } \\
\text { waterbirth) }\end{array}$ & $1.282 \mathrm{~m}^{2}$ \\
\hline 3 & Ruang UGD & $663 \mathrm{~m}^{2}$ \\
\hline 4 & Ruang Rawat Inap & $3.153 \mathrm{~m}^{2}$ \\
\hline 5 & Ruang Rawat Jalan & $399 \mathrm{~m}^{2}$ \\
\hline 6 & $\begin{array}{l}\text { Ruang Kegiatan } \\
\text { Penunjang } \\
\text { (Foodcourt, } \\
\text { Souvenir shop, } \\
\text { minimarket, dll.) }\end{array}$ & $1.143 \mathrm{~m}^{2}$ \\
\hline 7 & $\begin{array}{l}\text { Ruang Kegiatan } \\
\text { Pengelola }\end{array}$ & $863,5 \mathrm{~m}^{2}$ \\
\hline 8 & Ruang Utilitas & $332 \mathrm{~m}^{2}$ \\
\hline
\end{tabular}




\begin{tabular}{|c|c|c|}
\hline 9 & $\begin{array}{lll}\text { Ruang } & \text { Terbuka } \\
\text { Hijau \& } & \text { Healing } \\
\text { Garden } & \\
\end{array}$ & $1000 \mathrm{~m}^{2}$ \\
\hline & $\begin{array}{ll}\text { AL } & \text { LUAS } \\
\text { ILURUHAN }\end{array}$ & $11.482 \mathrm{~m}^{2}$ \\
\hline
\end{tabular}

Gambar 2. Tabel yang menunjukkan daftar kelompok ruang yang berada di Rumah Sakit Ibu dan Anak di Surakarta ini

Kemudian, berikut ini adalah bagan yang menunjukkan implementasi bagian bangunan mana yang sudah disortir untuk menjadi tempat diterapkankannya aspek-aspek Physical Outcome Theory di dalam Rumah Sakit Ibu dan Anak :

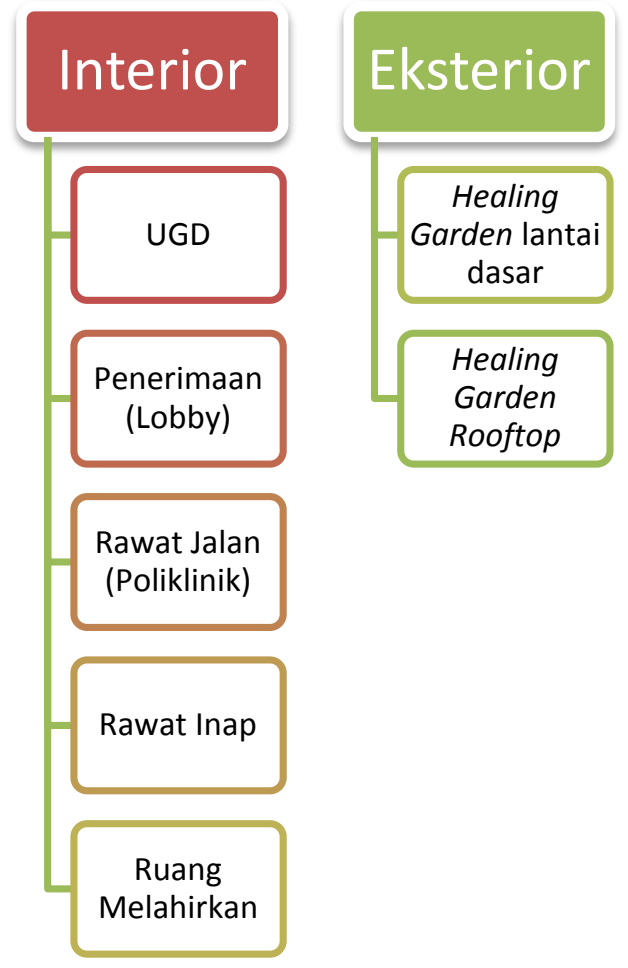

Gambar 3. Bagan yang menunjukkan ruang-ruang mana saja yang menjadi highlight penerapan aspek Physical Outcome Theory

Berikut adalah penerapan aspek-aspeknya ke dalam ruang-ruang tersebut :

\section{a. Nature (Alam)}

Nature yang dimaksud disini adalah alam sekitar site yang dapat bersifat alami dan buatan. Aspek Nature ini diterapkan pada Healing Garden yang berada di lantai dasar dan rooftop bangunan. Healing Garden ini sendiri adalah taman yang dapat digunakan sebagai sarana rekreasi dan penyembuhani untuk pasien, guna menyegarkan jasmani dan rohani mereka. Healing Garden ini sendiri memiliki beberapa kriteria (Balmergy, 2013), yaitu :

a) Memiliki gerbang/pagar pembatas

b) Memiliki ruang tersendiri untuk areanya

c) Memiliki jalan setapak

d) Memiliki area duduk dan berteduh

e) Dapat sebagai habitat satwa liar seperti burung, kupu-kupu, dan lain-lain

f) Memiliki elemen air

Di bawah ini merupakan gambar yang menunjukkan aspek alam dan kriteria healing garden di dalam desain tersebut :

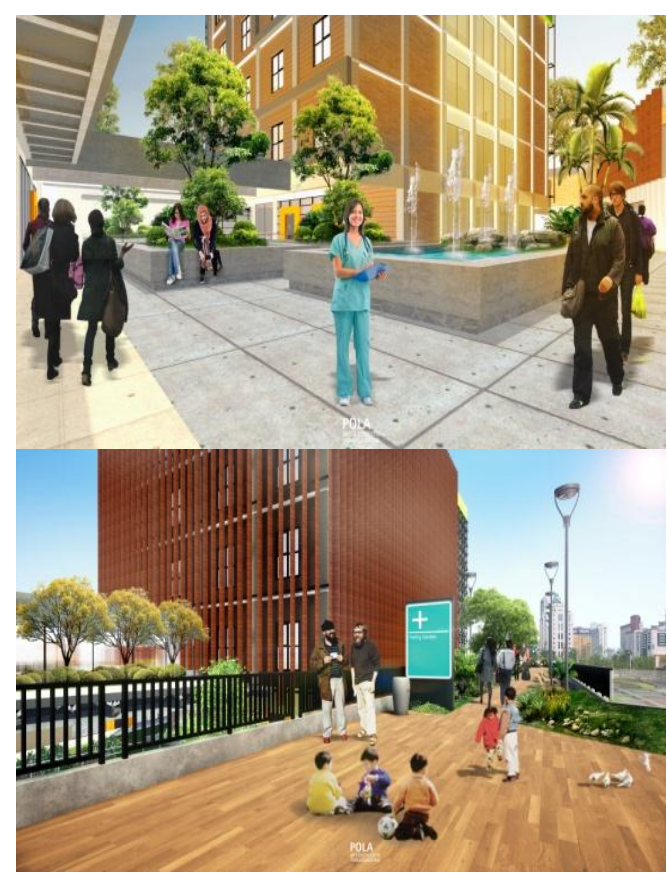

Gambar 4. Alam buatan yang diterapkan/dibuat di area Healing Garden, berupa sebuah taman yang berada di lantai dasar bangunan (atas) dan taman di rooftop bangunan (bawah)

\section{b. $\quad$ Fresh Air (Udara Segar)}

Udara segar yang dimaksud adalah udara alami dan buatan yang berada di sekitar dan didalam bangunan. Udara buatan didalam bangunan didapat dari pemasangan air conditioner didalam ruang. Sedangkan, udara alami didapat dari vegetasi-vegetasi yang ditanam di sekitar 
site dan didalam site. Vegetasi ini sendiri banyak terdapat di Healing Garden Area, sehingga diharapkan vegetasi ini dapat membantu meredakan polusi udara yang didapat dari jalan raya di selatan site. Vegetasi yang ditanam juga memiliki kriteria khusus yang dapat memiliki fungsi lain untuk pengguna bangunan. Kriteria tersebut adalah, vegetasi tersebut harus termasuk kelompok vegetasi sebagai berikut :

a) Vegetasi Peneduh, yaitu berupa pohon flamboyan dan pohon ketapang

b) Vegetasi Aromaterapi, yaitu berupa tanaman bunga-bungaan seperti bunga mawar, melati, sedap malam

c)Vegetasi Groundcover, yaitu berupa rumputrumputan seperti rumput gajah

Udara yang bersih dan segar ini sendiri juga bisa didapat dari sistem cross ventilation pada ruang-ruang lain yang ada didalam bangunan. Gambar dibawah menunjukkan penerapan peletakan vegetasi yang ada di sekitar site :

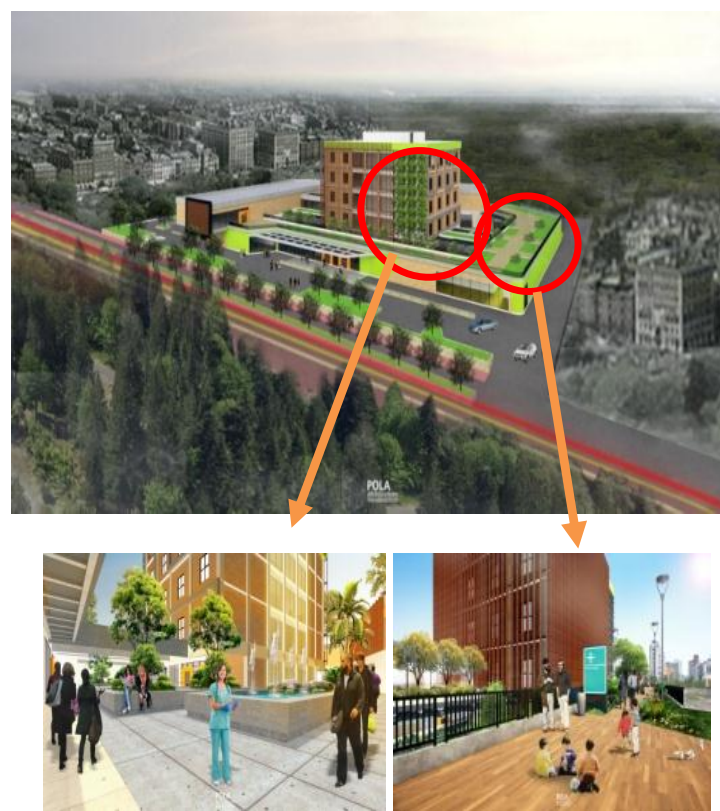

Gambar 5. Vegetasi yang ditanam di sekitar site menciptakan adanya udara bersih di sekitar site

\section{c. $\quad$ Noise (Suara/Kebisingan)}

Kebisingan yang terdapat di sekitar site, harus dapat diredam dengan baik oleh vegetasivegetasi yang ada di dalam site. Vegetasi yang dapat meredam kebisingan contohnya adalah pohon yang memiliki tajuk yang tebal dan daun rindang, seperti pohon jati emas dan bambu jepang. Selain vegetasi yang ada didalam site, pemasangan pintu dan jendela yang benar kerapatannya, juga dapat membantu meredam kebisingan dari dalam maupun luar bangunan. Selain itu, tembok yang tebal dan diberi peredam suara juga berguna untuk meredam kebisingan yang tingkatnya tinggi, terutama cocok diterapkan untuk kamar-kamar rawat inap, seperti pada gambar 6:

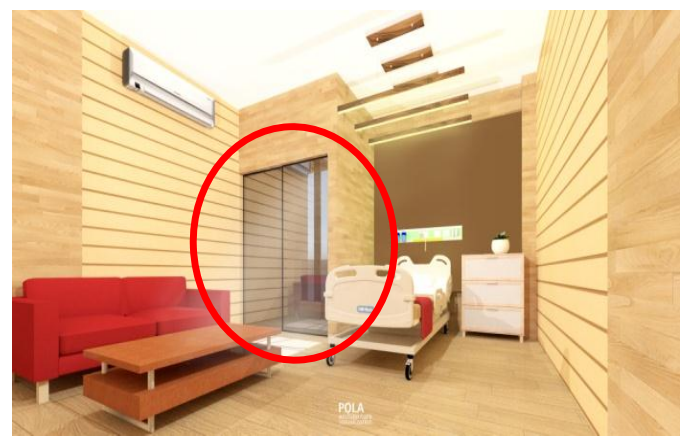

Gambar 6. Pemasangan kaca yang rapat dan penggunaan material dinding yang tepat dapat meredam kebisingan pada ruang rawat inap

Sedangkan berikut ini adalah peletakan vegetasi sebagai peredam kebisingan dari dalam dan luar site :

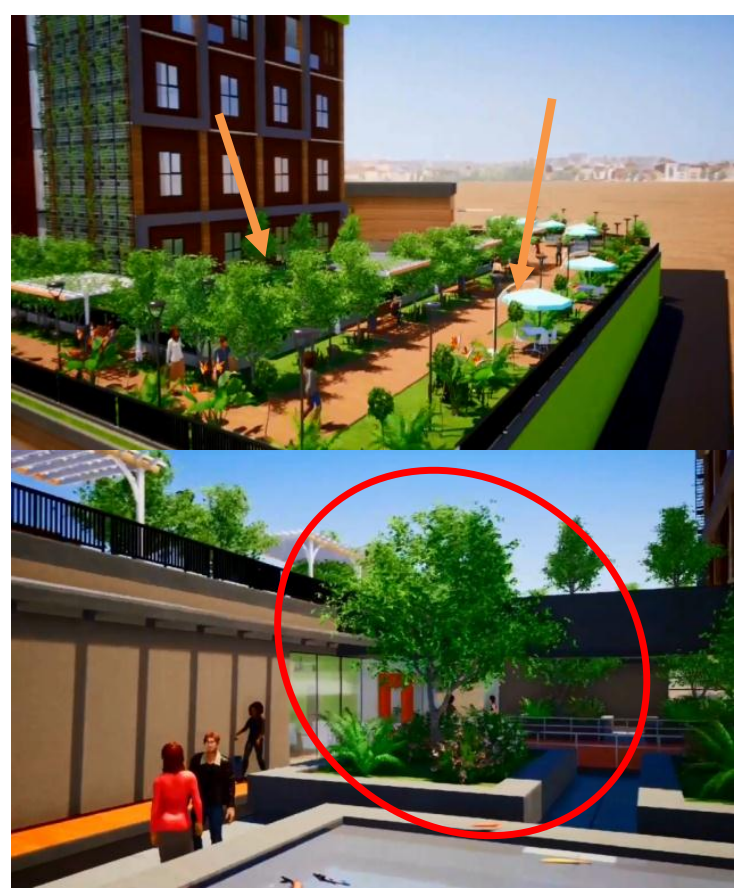

Gambar 7. Gambar atas menunjukkan area healing garden yang berada di rooftop dan gambar di

bawahnya menunjukkan area healing garden yang berada di lantai dasar. Keduanya menampilkan 
peletakan banyak vegetasi yang berfungsi untuk meredam kebisingan dari dalam dan luar site.

\section{d. $\quad$ Light (Cahaya)}

Cahaya yang dimaksud adalah cahaya alami (yang berasal dari cahaya matahari) dan cahaya buatan yang berasal dari lampu-lampu yang dipasang dalam interior maupun eksterior bangunan. Guna mendapatkan cahaya alami yang maksimal, maka diperbanyaklah bukaan bukaan pada setiap ruang, agar setiap ruang mendapatkan cahaya alami yang cukup. Selain itu, bukaan pada tiap ruang juga nantinya berguna untuk penghawaan alami (cross ventilation). Tidak hanya mendapat cahaya buatan dari lampu pijar yang terpasang. Namun apabila terpaksa tidak dapat membuat bukaan yang cukup, lampu pijar juga haruslah yang tidak menimbulkan efek menyilaukan dan harus yang memberikan efek nyaman untuk penghilatan pasien dan pengunjung. Berikut adalah salah satu contoh ruang yang menggunakan pencahayaan ganda (alami dan buatan) pada bangunan rumah sakit ini :

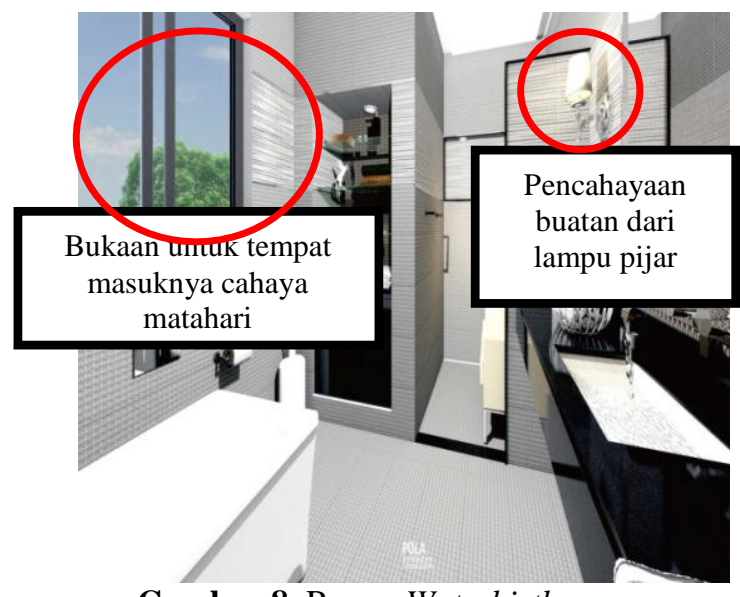

Gambar 8. Ruang Waterbirth yang menggunakan pencahayaan ganda (alami \& buatan)

Sedangkan berikut ini adalah contoh ruangan yang tidak terlalu banyak mendapatkan cahaya alami sehingga harus memaksimalkan cahaya buatan dari lampu :

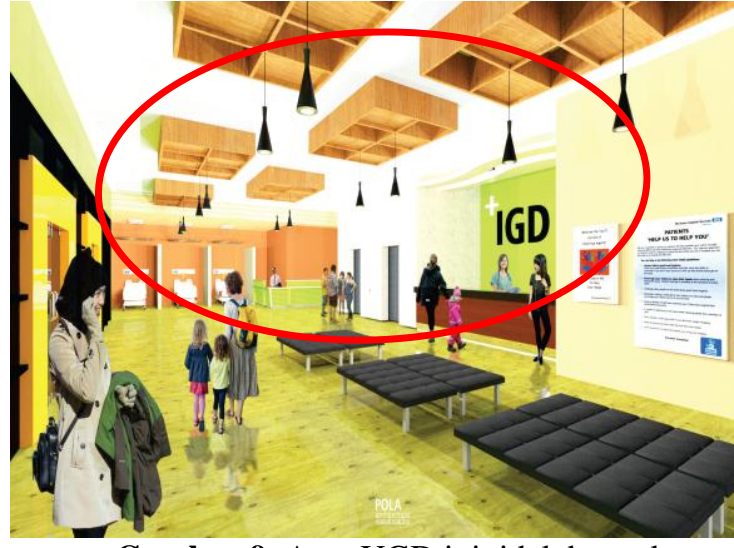

Gambar 9. Area UGD ini tidak banyak mendapatkan cahaya alami sehingga harus banyak mendapatkan cahaya buatan dari lampu pijar yang diletakkan pada plafond-plafond nya.

Namun, tidak semua cahaya matahari akan bagus untuk para pengguna bangunan, ada juga yang justru akan menyilaukan pandangan sehingga akan mengganggu kenyamanan pengguna terutama pada bangsal rawat inap. Sehingga, dibuatlah pula sun shading pada bangunan ini yang terletak di bagian selatan dan barat bangunan. Seperti terlihat pada gambar di bawah ini :

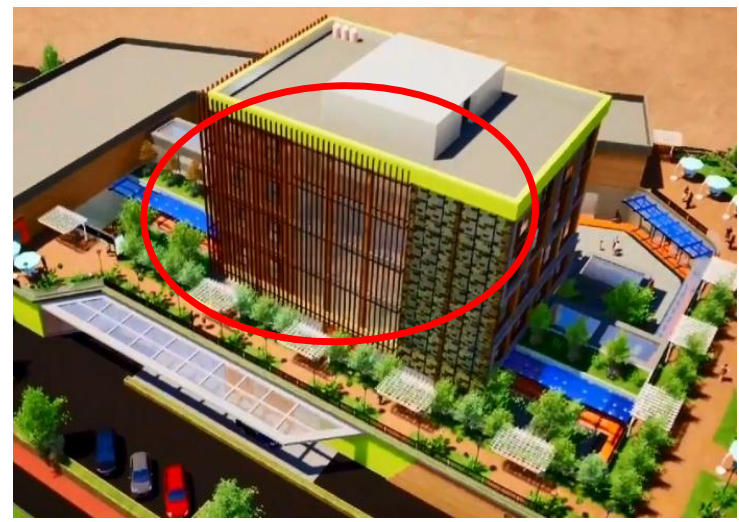

Gambar 10. Sun shading yang terpasang pada bagian selatan dan barat bangunan rawat inap.

Terdapat pula vertical garden disampingnya yang berfungsi untuk penghijauan area.

e. Psychologycal Aspect (Aspek

Psikologis)

Aspek psikologi yang diterapkan pada bangunan adalah aspek warna, instalasi seni, aroma dan view. Tidak semua aspek akan berhasil diterapkan pada 1 ruang penuh, namun sekiranya dalam 1 ruangan, terdapat setidaknya salah satu aspek psikologis yang disebutkan 
diatas tadi. Berikut adalah contoh penerapan psikologi warna dan pengaruhnya terhadap pasien :

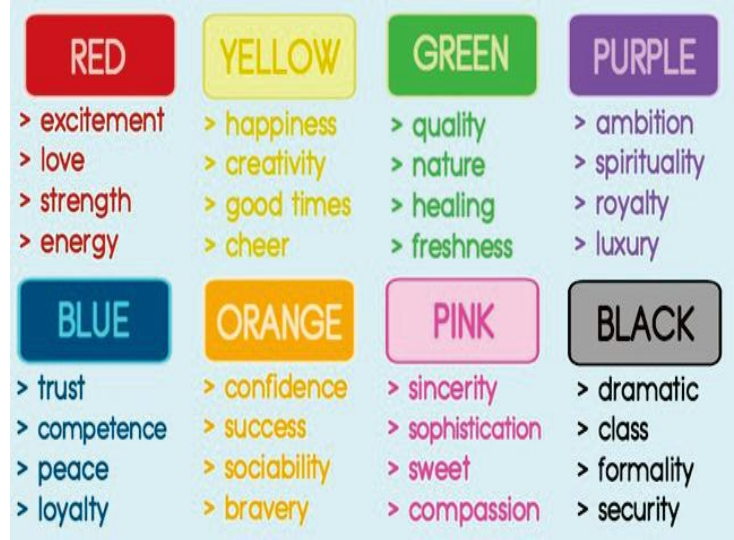

Gambar 11. Psikologi warna dan pengaruhnya terhadap manusia

Kemudian di gambar 12 ini adalah contoh ruangan yang dapat diterapkan beberapa aspek psikologi seperti contoh-contoh diatas:

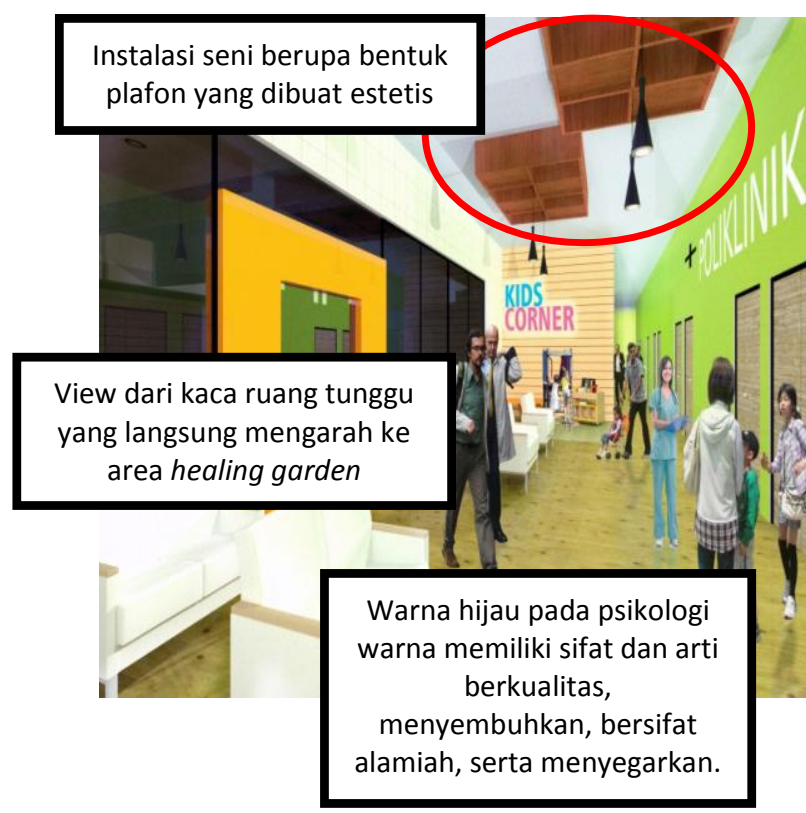

Gambar 12. Area Poliklinik (rawat jalan) yang memiliki sebagian besar aspek psikologis yang dapat mempengaruhi pasien secara rohani

Dari semua aspek-aspek yang digabungkan diatas, maka muncul-lah sebuah desain yang merupakan sebuah kesatuan dari penerapan Physical Outcome Theory, bangunan tersebut berada pada site seperti yang ditunjukkan pada gambar 10 dibawah ini :

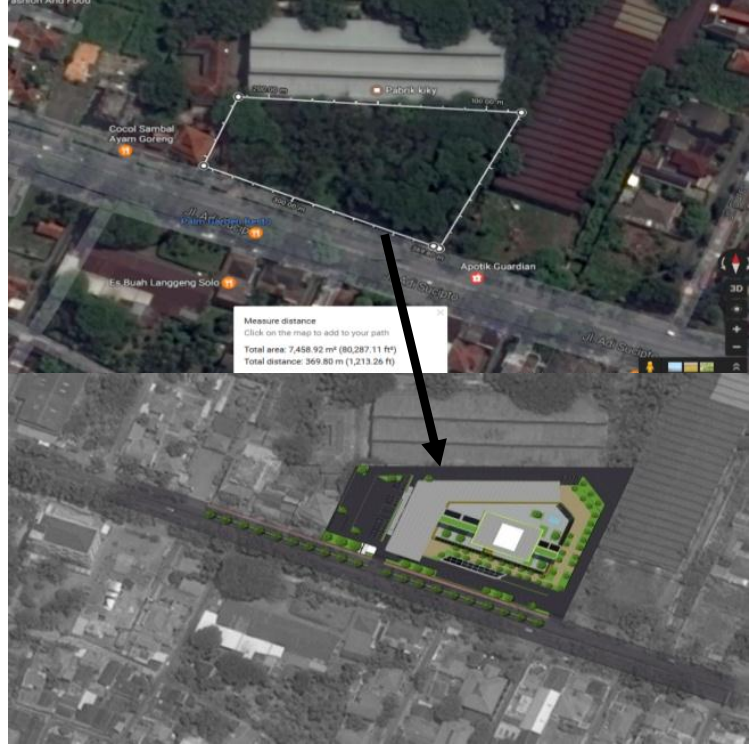

Gambar 13. Site bangunan dan hasil pengolahannya pada blockplan bangunan Rumah sakit Ibu dan Anak di Surakarta

\section{Nama Bangunan}

: Rumah Sakit Ibu dan

Anak di Surakarta

Lokasi

: Jalan Laksamana Adi

Sucipto, Kecamatan Laweyan, Kota Surakarta

Batas batas tapak meliputi :

a. Utara : Lahan Kosong Bekas Pabrik Kertas Kiky

b. Timur : Lahan Kosong, Permukiman Warga (Jl. Duren), SDN Karangasem 2, Gedung Purna Yudha

c. Selatan : Jalan Raya Adi Sutjipto, Permukiman Warga

d. Barat : Permukiman Warga

Luas lahan $\quad: 7.500 \mathrm{~m}$

Jumlah lantai $\quad: 2$ lantai dan 5 lantai

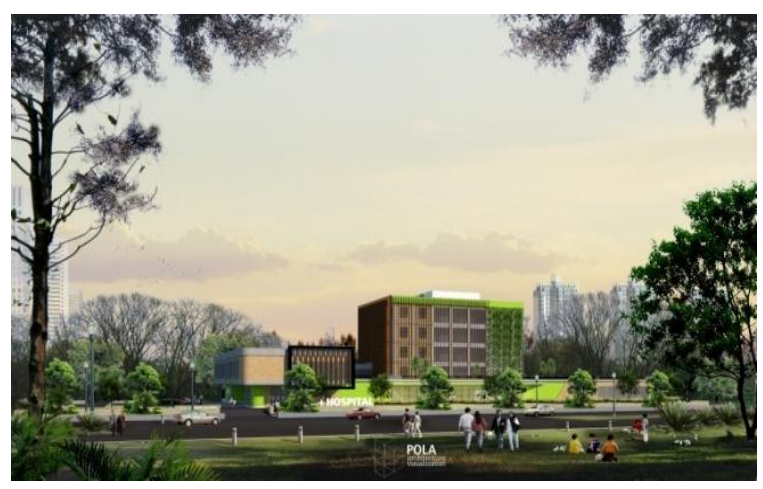




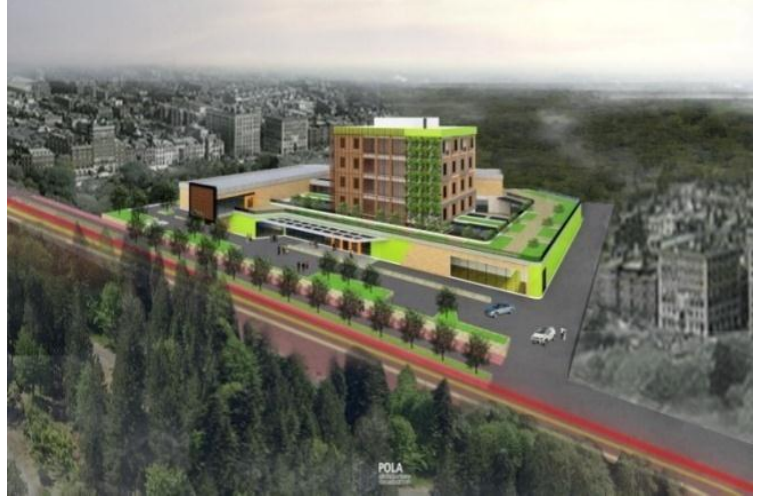

Gambar 14. Perspektif Eksterior Bangunan Rumah Sakit Ibu dan Anak di Surakarta

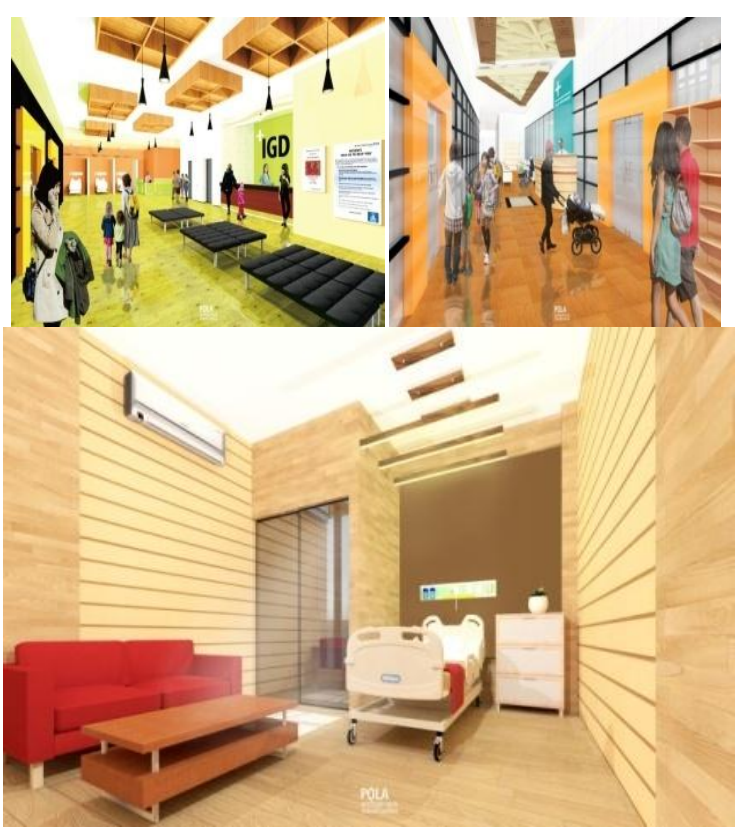

Gambar 15. Perspektif Interior Bangunan Rumah Sakit Ibu dan Anak di Surakarta

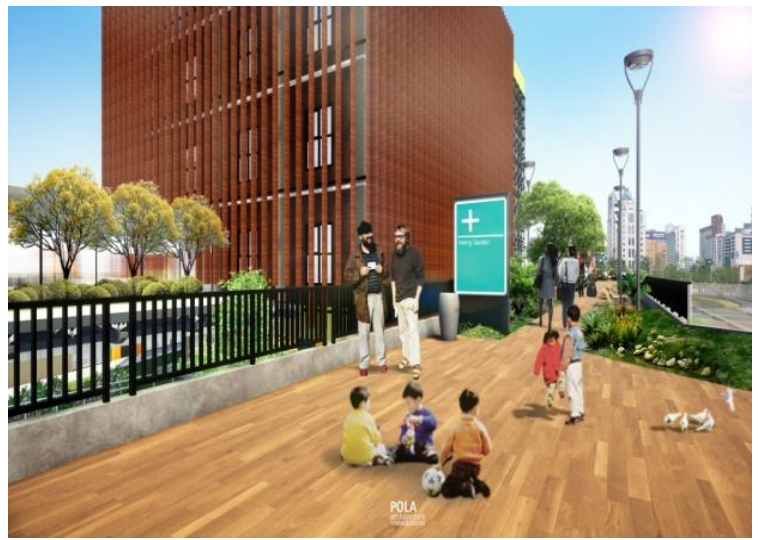

Gambar 16. Perspektif Healing Garden pada rooftop area Bangunan Rumah Sakit Ibu dan Anak di Surakarta

Dari semua kesatuan desain tersebut, maka juga terbentuklah sebuah zoning bangunan yang sesuai dengan Physical Outcome Theory seperti pada gambar di bawah ini :

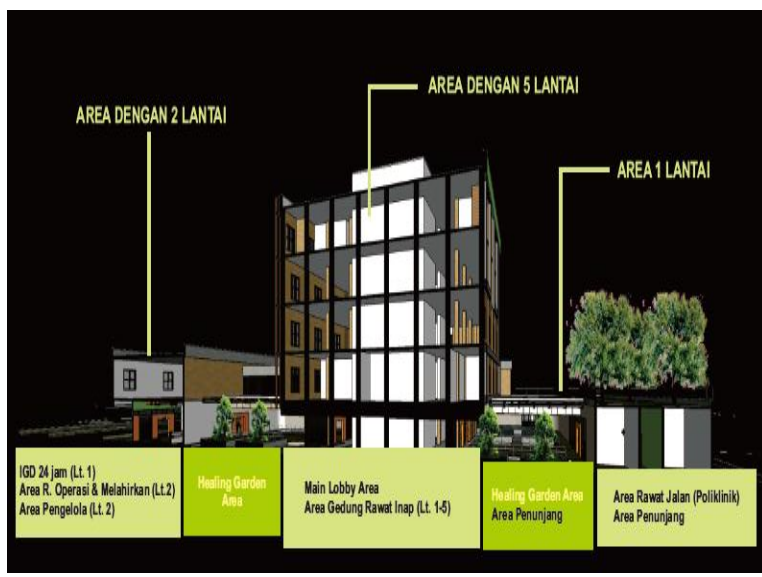

Gambar 17. Zoning bangunan yang menunjukkan area-area ruang didalam bangunan. Bangunan terdiri atas 2 lantai, 5 lantai di bagian tengah, dan 1 lantai pada bagian depan

Zoning bangunan tersebut menunjukkan bahwa bangunan terdiri dari area-area yang sudah dikelompokkan menurut fungsinya masingmasing dan sesuai dengan Physical Outcome Theory, yaitu sebagai berikut :

\begin{tabular}{|l|l|c|}
\hline No. & \multicolumn{1}{|c|}{ Kelompok Ruang } & Letak \\
\hline 1 & $\begin{array}{l}\text { Penerimaan } \\
\text { (Lobby, parkir, dll.) }\end{array}$ & $\begin{array}{l}\text { Lt. 1 \& 2 } \\
\text { (Triase, Resusitasi, } \\
\text { Penanganan, dll.) }\end{array}$ \\
\hline 3 & $\begin{array}{l}\text { Rawat Jalan } \\
\text { (Poliklinik) }\end{array}$ & Lt. 1 \\
\hline 4 & Rawat Inap & Lt. 1-5 \\
\hline 5 & Pengelola & Lt. 2 \\
\hline 6 & $\begin{array}{l}\text { Penunjang } \\
\text { (Souvenir } \\
\text { minimarket, apotek, } \\
\text { foodcourt, dll) }\end{array}$ & Lt. 1 \\
\hline 7 & Servis & $\begin{array}{l}\text { Lt. 1 \& } \\
\text { Rooftop }\end{array}$ \\
\hline 8 & \begin{tabular}{l} 
Healing Garden \\
\hline
\end{tabular}
\end{tabular}

Gambar 18. Tabel yang menunjukkan kelompok ruang dan letak-letak ruang tersebut berada di dalam bangunan

Sedangkan dibawah ini adalah hal yang tidak kalah penting, yaitu sistem utilitas pada bangunanrumah sakit ini, dikarenakan rumah sakit digolongkan sebagai bangunan yang 
memiliki sistem utilitas 'khusus', maka berikut ini adalah gambaran sistemnya secara garis besar :

\section{ROOFTANK}

\section{PLN\& GENSET}

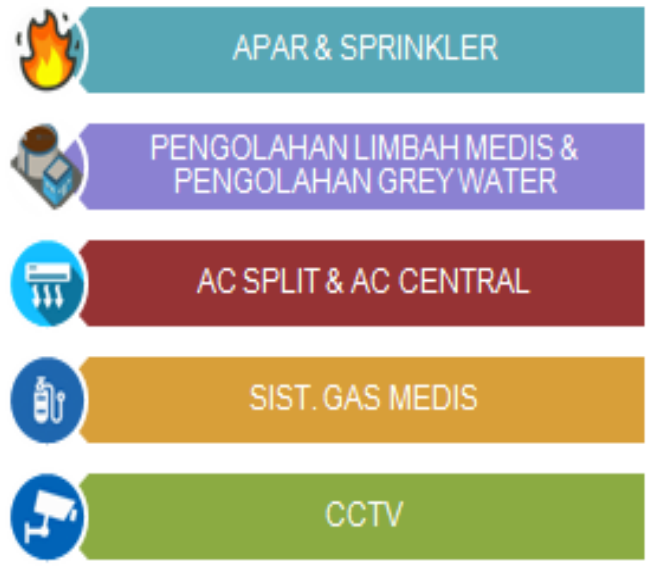

Gambar 19. Gambar yang menunjukkan sistem utilitas pada rumah sakit ini

Sistem utilitas yang khusus dan berbeda dari bangunan lain adalah sistem pengolahan limbah medis rumah sakit, yaitu adalah seperti yang dijelaskan oleh gambar berikut ini :

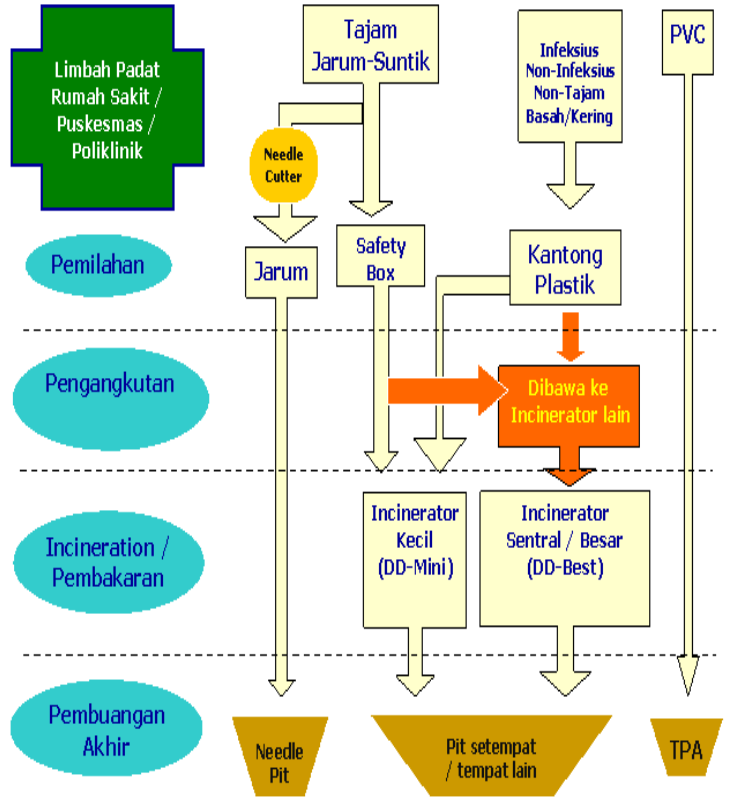

Gambar 20. Sistem pengolahan limbah medis pada rumah sakit

\section{KESIMPULAN}

Rumah Sakit Ibu dan Anak berfungsi sebagai fasilitas kesehatan yang memfasilitasi ibu hamil beserta bayinya, wanita dengan masalah reproduksinya, dan anak-anak dibawah 18 tahun, harus memiliki fungsi untuk menyembuhkan pasiennya dengan baik dan secara cepat. Oleh sebab itu, diperlukannya penerapan Physical Outcome Theory pada bangunan rumah sakit ini untuk menunjang keberhasilan tujuan tersebut. Teori tersebut menghasilkan sebuah temuan pedoman perancangan sebagai berikut :

a. $\quad$ Nature

Alam alami maupun buatan merupakan unsur penting yang harus ada di dalam desain, mengingat manusia pada hakekatnya berasal dari alam dan akan kembali kepada alam pula nantinya.

b. Fresh Air

Udara bersih juga dapat membantu penyembuhan pasien secara cepat karena pada umumnya udara yang bersih akan lebih banyak mengandung oksigen dibanding karbondioksida yang bersifat racun. Udara bersih itu sendiri dapat didapat dari vegetasivegetasi yang diletakkan di dalam maupun luar bangunan.

c. Noise

Pentingnya meredam kebisingan di dalam dan diluar bangunan agar pasien dapat beristirahat dengan lebih tenang dan nyaman di dalam rumah sakit.

\section{d. Light}

Pencahayaan adalah unsur yang amat penting pada bangunan. Terutama pencahayaan alami dari cahaya matahari karena dapat membantu pembentukan Vitamin D pada manusia. Cahaya buatan juga diperlukan utamanya di saat malam hari.

e. $\quad$ Psychologycal Aspect

Pengaturan aspek psikologi seperti warna, seni, aroma, dan lain sebagainya dapat mempengaruhi otak manusia dengan signifikan sehingga dapat memberikan sugesti yang positif terhadap perasaan mereka apabila berada di sebuah ruang.

Desain Rumah Sakit Ibu dan Anak di Surakarta dengan penerapan Physical Outcome Theory diharapkan dapat menciptakan sebuah fasilitas kesehatan yang aman dan nyaman bagi para ibu 
dan anak, serta diharapkan dapat membantu menurunkan angka kematian ibu dan anak akibat dari kurangnya penanganan kesehatan, terutama di kota Surakarta dan Indonesia.

\section{REFERENSI}

Balmergy, H. M. (2013). Healing Garden Accreditation Tool.

Berg, V. d. (2005). Health Impact of Healing Environments (a review of evidence for benefits of nature, daylight, fresh air, and quiet in healthcare settings). .

Djikstra, K. (2009). Effects of Physical Environmental Stimuli on Patiens' Effects of Health and Well-Being. 